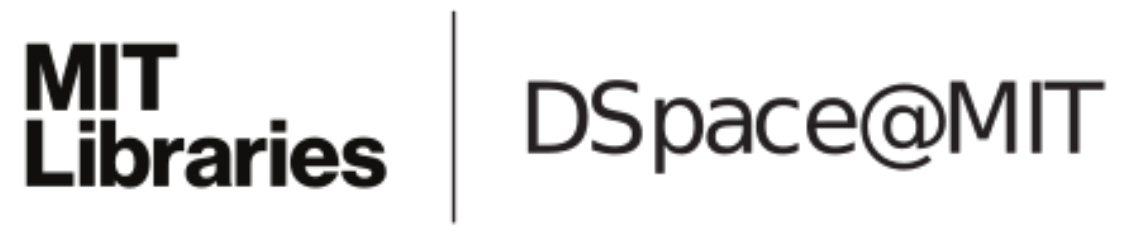

MIT Open Access Articles

Seismic evidence for thermal runaway during intermediate-depth earthquake rupture

The MIT Faculty has made this article openly available. Please share how this access benefits you. Your story matters.

Citation: Prieto, German A., Manuel Florez, Sarah A. Barrett, Gregory C. Beroza, Patricia Pedraza, Jose Faustino Blanco, and Esteban Poveda. "Seismic Evidence for Thermal Runaway During Intermediate-Depth Earthquake Rupture." Geophysical Research Letters 40, no. 23 (December 6, 2013): 6064-6068. (c) 2013 American Geophysical Union

As Published: http://dx.doi.org/10.1002/2013gl058109

Publisher: American Geophysical Union (AGU)

Persistent URL: http://hdl.handle.net/1721.1/97899

Version: Final published version: final published article, as it appeared in a journal, conference proceedings, or other formally published context

Terms of Use: Article is made available in accordance with the publisher's policy and may be subject to US copyright law. Please refer to the publisher's site for terms of use. 


\title{
Seismic evidence for thermal runaway during intermediate-depth earthquake rupture
}

\author{
Germán A. Prieto, ${ }^{1}$ Manuel Florez, ${ }^{1}$ Sarah A. Barrett, ${ }^{2}$ Gregory C. Beroza, ${ }^{2}$ Patricia Pedraza, ${ }^{3}$ \\ Jose Faustino Blanco, ${ }^{3}$ and Esteban Poveda ${ }^{3}$ \\ Received 24 September 2013; revised 12 November 2013; accepted 18 November 2013.
}

[1] Intermediate-depth earthquakes occur at depths where temperatures and pressures exceed those at which brittle failure is expected. There are two leading candidates for the physical mechanism behind these earthquakes: dehydration embrittlement and self-localizing thermal shear runaway. A complete energy budget for a range of earthquake sizes can help constrain whether either of these mechanisms might play a role in intermediate-depth earthquake rupture. The combination of high stress drop and low radiation efficiency that we observe for $M_{w} 4-5$ earthquakes in the Bucaramanga Nest implies a temperature increase of $600-1000^{\circ} \mathrm{C}$ for a centimeter-scale layer during earthquake failure. This suggests that substantial shear heating, and possibly partial melting, occurs during intermediate-depth earthquake failure. Our observations support thermal shear runaway as the mechanism for intermediate-depth earthquakes, which would help explain differences in their behavior compared to shallow earthquakes. Citation: Prieto, G. A., M. Florez, S. A. Barrett, and G. C. Beroza (2013), Seismic evidence for thermal runaway during intermediate-depth earthquake rupture, Geophys. Res. Lett., 40, doi:10.1002/2013GL058109.

\section{Introduction}

[2] Intermediate-depth earthquakes occur at depths of 50 to $300 \mathrm{~km}$ in subducting lithosphere [Frohlich, 2006]. Despite their ubiquity in earthquake catalogs, their physical mechanism remains unclear because ambient temperatures and pressures are expected to lead to ductile, rather than brittle, deformation [Green and Houston, 1995; Frohlich, 2006].

[3] A leading mechanism for intermediate-depth earthquakes is dehydration embrittlement [Green and Houston, 1995; Hacker et al., 2003; Frohlich, 2006; Houston, 2007], which posits that earthquakes are triggered by the release of fluids during metamorphic dehydration reactions, raising the pore pressure and permitting brittle failure [Hacker et al., 2003; Houston, 2007]. Recent high-pressure laboratory

Additional supporting information may be found in the online version of this article.

${ }^{1}$ Department of Earth, Atmospheric and Planetary Sciences, Massachusetts Institute of Technology, Cambridge, Massachusetts, USA.

${ }^{2}$ Department of Geophysics, Stanford University, Palo Alto, California, USA.

${ }^{3}$ Servicio Geológico Colombiano, Bogotá, Colombia.

Corresponding author: G. A. Prieto, Department of Earth, Atmospheric and Planetary Sciences, Massachusetts Institute of Technology, 77 Massachusetts Ave., Cambridge, MA 02139 USA. (gprieto@mit.edu)

(C)2013. American Geophysical Union. All Rights Reserved. 0094-8276/13/10.1002/2013GL058109 experiments [Jung et al., 2004, 2009] have presented evidence for brittle deformation associated with dehydration, but others [Chernak and Hirth, 2011] have observed ductile deformation instead, raising the question of whether unstable fault behavior can in fact be enabled by dehydration at high pressures.

[4] An alternative mechanism invokes the presence of highly localized viscous creep leading to increases in temperature, weakening, and further slip in a narrow shear zone-a positive feedback mechanism referred to as a thermal shear instability [Keleman and Hirth, 2007; Braeck and Podladchikov, 2007; Houston, 2007; John et al., 2009]. Laboratory experiments of frictional properties at seismic slip velocities [Di Toro et al., 2006; Del Gaudio et al., 2009; Di Toro et al., 2011] and field observations of mafic and ultramafic rocks in subduction settings [Obata and Karato, 1995; Ueda et al., 2008] both show evidence of extremely high temperatures in the form of pseudotachylites, which are glassy veins formed by fast melting during seismic slip. The only seismological evidence we are aware of for high-temperature rise and inferred frictional melting is for the deep $M_{w} 8.2$ earthquake in Bolivia [Kanamori et al., 1998; Bouchon and Ihmle, 1999].

[5] We present a complete source parameter and energy budget analysis for $253 M_{w} 3.2-5.2$ intermediate-depth earthquakes in the Bucaramanga Nest (BN), Colombia. The BN is the densest concentration of intermediate-depth earthquakes (140-160 km depth) in the world, with an estimated source region extending $5 \times 5 \mathrm{~km}$ horizontally and no more than $20 \mathrm{~km}$ vertically [Prieto et al., 2012]. Although it may appear as a highly unusual feature, the BN's seismicity shares similar behavior with other intermediate-depth and deep earthquakes, including their tectonic setting within or along subducting slabs, high $b$ values, low aftershock productivity, and high average stress drops [Frohlich and Nakamura, 2009; Prieto et al., 2012]. Since 1993, the RSNC (Red Sísmica Nacional de Colombia), a regional seismic network, has digitally recorded over 80,000 earthquakes in the Bucaramanga Nest, making this an ideal natural laboratory to study the source process of intermediate-depth earthquakes.

\section{Source Parameter Scaling}

[6] We estimate source spectra for both $P$ and $S$ waves using a spectral stacking technique that isolates source from path effects [Prieto et al., 2004]. Because all earthquakes are collocated, our stacking technique will apply similar frequency-dependent attenuation and site-effect corrections to all source spectral estimates under the empirical Green's function approximation [Allmann and Shearer, 2009]. From the source spectra, we determine static source parameters (seismic moment, rupture area, slip, corner frequencies, and stress drops) and dynamic source parameters (radiated seismic 


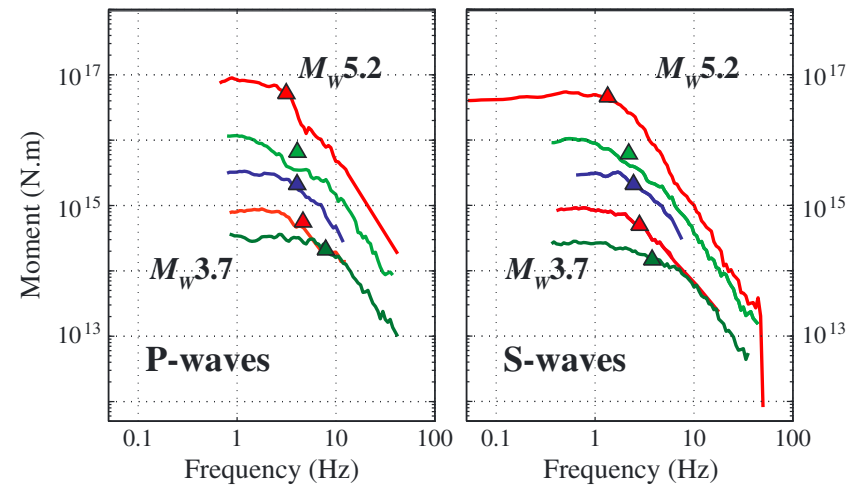

Figure 1. Selected source spectral estimates. Example $P$ and $S$ wave source spectra obtained using the stacking method and estimated corner frequencies assuming a Brune spectral model (triangles). Spectral estimates represent individual earthquakes. The same signals are used to calculate the radiated energy and apparent stress, although extrapolation at low and high frequencies is required to avoid underestimating radiated energy.

energy and apparent stress). Figure 1 shows examples of $P$ and $S$ wave source spectra and corner frequency estimates using a Brune spectral model [Brune, 1970].

[7] Based on the observed corner frequencies and seismic moments, we calculate the static stress drop $\Delta \sigma$, while the radiated energy and apparent stress $\sigma_{\alpha}$ are estimated by integrating the velocity-squared spectrum after extrapolating the observed spectra assuming a $\omega^{-2}$ decay at high frequencies (see supporting information for methodology). The highfrequency spectral falloff we observe for larger earthquakes is usually faster than $\omega^{-2}$, suggesting that this extrapolation may lead to an overestimate of radiated energy, particularly for small events.

[8] Figure 2 shows that stress drop exhibits a clear increase with magnitude $\left(\Delta \sigma \sim M_{0}{ }^{0.4}\right)$ and that stress drop is about 100 times larger than the apparent stress for most events in the Bucaramanga Nest. This combination indicates a strongly dissipative source process because the large static stress drops do not translate into strong high-frequency radiation. The average radiation efficiency $\eta_{R}$ of 0.022 is similar to the value of $\eta_{R}=0.04$ obtained for the deep Bolivia $M_{w} 8.2$ earthquake [Kanamori et al., 1998].

[9] The strong scaling of stress drop observed in Figure 2 reflects a major difference from shallow earthquakes [e.g., Allmann and Shearer, 2009]. Although previous studies of stress drop scaling for deep earthquakes have suggested little or no scaling [Frohlich, 2006], we believe that the scaling we observe is robust. Within the magnitude range $3.5<M_{w}<5.2$, other studies of deep- and intermediate-depth earthquakes have reported no [e.g., Kikuchi and Ishida, 1993; Gusev et al., 2002] or some scaling [Radulian and Popa, 1996; Oth et al., 2009]. Our results are based on a larger number of stations, a wider frequency band, and smaller epicentral distances compared to previous studies. Our corner frequency estimates are well within the frequency range of the data, so we do not expect to be underestimating stress drops for smaller earthquakes. $P$ wave corner frequency estimates for the magnitude range $M_{w} 4-5$ range between 2 and $8 \mathrm{~Hz}$, a range with good signal-to-noise ratio, where the strong scaling of stress drops is readily observed.

\section{Energy Budget and Temperature Rise for Intermediate-Depth Earthquakes}

[10] We use macroscopic source parameters to estimate the fracture energy per unit area $G\left(\mathrm{~J} / \mathrm{m}^{2}\right)$ for these earthquakes. Following Abercrombie and Rice [2005; hereafter A\&R] and assuming no undershoot or overshoot, we estimate the fracture energy as

$$
G=\frac{1}{2}\left(\Delta \sigma-2 \sigma_{a}\right) S,
$$

where $S$ is the average slip on the fault (see figure 3). For both shallow and intermediate-depth earthquakes, the fracture energy increases with increasing slip. By fitting $G$ as a function of slip $S$, we derive a slip-weakening function of the form

$$
\sigma_{f}(S) \propto-300 * S^{0.8},
$$

compared to results for shallow earthquakes obtained in $A \& R$

$$
\sigma_{f}(S) \propto-24 * S^{0.28} .
$$

[11] The dynamic friction $\sigma_{f}$ begins with a value $\sigma_{0}$ that increases to a peak stress $\sigma_{\mathrm{p}}$ when slip begins and then decreases to a final value $\sigma_{\mathrm{d}}$. The data from shallow earthquakes [A\&R] suggest that the decrease is initially rapid and then levels off. Intermediate-depth earthquakes show a different behavior, with a continuing decrease of frictional resistance with increasing slip, leading to substantially larger fracture energy for larger earthquakes.

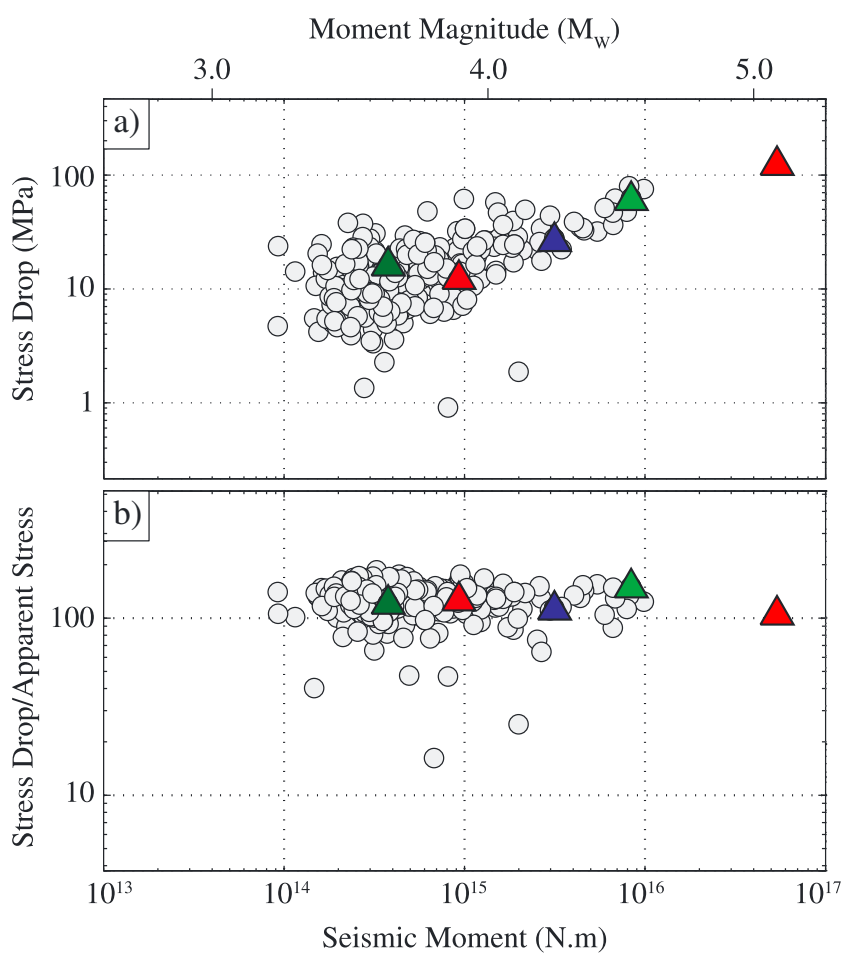

Figure 2. Static and dynamic earthquake source parameters. (a) Stress drops and (b) ratio of stress drop and apparent stress as a function of seismic moment. Colored triangles represent estimates for the events shown in Figure 1. Note that most earthquakes have an average ratio of $\sim 100$ compared to a ratio of $\sim 2$ for a constant friction model, where fracture energy is negligible. Stress drop is estimated assuming $V_{R}=0.9 \beta$. 


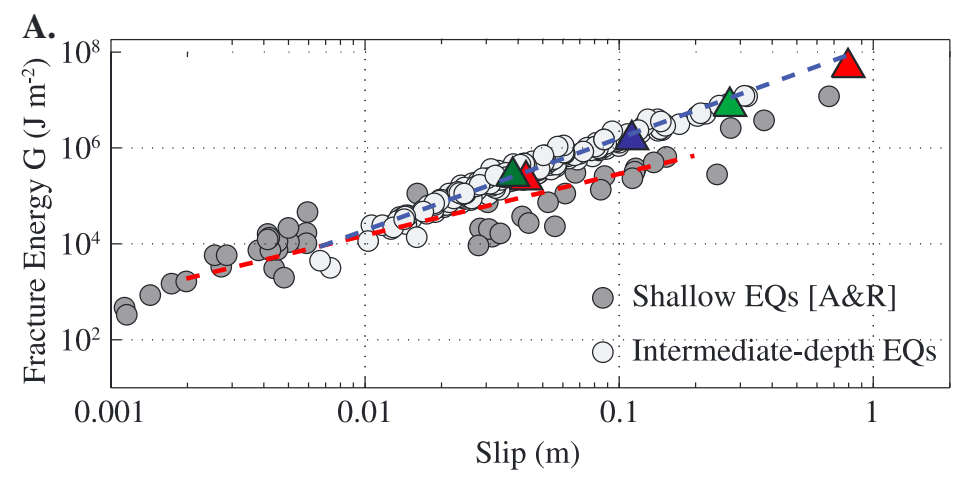

B.
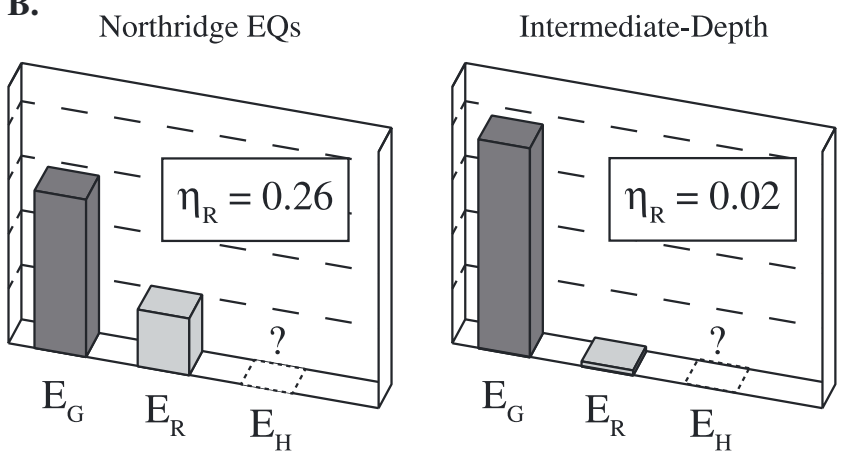

$$
\begin{aligned}
& \mathrm{E}_{\mathrm{G}}=\mathrm{GA} \\
& \mathrm{E}_{\mathrm{R}}-\text { Radiated }
\end{aligned}
$$

Frictional Energy $\left(\mathrm{E}_{\mathrm{H}}\right)$ is unknown

Figure 3. Fracture energy and energy partitioning of earthquake rupture for shallow and intermediate-depth earthquakes. (a) Proxy for fracture energy per unit area $G\left(\mathrm{~J} / \mathrm{m}^{2}\right)$ estimated as a function of slip [A\&R]. Data from Cajon Pass and the Northridge aftershocks are included for comparison. The relationship of $G$ and slip $S$ follows a power law with an exponent of 1.28 (red dashed line) for the shallow earthquakes [Abercrombie and Rice, 2005] and 1.85 for the Bucaramanga Nest earthquakes (blue dashed line). Colored triangles represent estimates for the events shown in Figure 1. Regardless of the power law scaling, our results show that fracture energy is higher for intermediate-depth earthquakes than shallow earthquakes with similar slip. (b) Bar charts show the median partitioning of energy for shallow and intermediate-depth earthquakes. Because $E_{H}$ cannot be determined, we show only the fracture energy as estimated in Figure $3 \mathrm{a}$ and the radiated seismic energy estimated from the source spectra. Intermediate-depth earthquakes on average show a smaller proportion of radiated seismic energy, leading to low radiation efficiencies $\left(\eta_{R}\right)$ and suggesting a strongly dissipative mechanism.

[12] For events with $0.02-1.0 \mathrm{~m}$ of slip, intermediate-depth earthquake fracture energy per unit area $(G)$ is approximately one order of magnitude larger than for shallow earthquakes. If we analyze this range only, the power law behavior of shallow earthquakes is similar to what we observe for intermediate-depth earthquakes. Nevertheless, for the same seismic moment, intermediate-depth earthquakes suffer much higher stress drops and have lower radiation efficiency than their shallow counterpart (see Figure 3). That means, the same amount of slip is concentrated on a much smaller fault area, yet it radiates less seismic energy in the case of intermediate-depth earthquakes, reflecting higher dynamic strength [Beeler et al., 2003].

[13] From the source parameter and fracture energy estimates (equation (1)) we calculate the temperature rise $\Delta T$ due to slip on a finite width fault assuming adiabatic conditions [Cardwell et al., 1978]:

$$
\begin{gathered}
Q=G A=C \Delta T m, \\
G=C \Delta T \rho w,
\end{gathered}
$$

where $Q$ represents energy that is converted to heat, $A$ is the rupture area, $m$ the mass of peridotite to be melted, $\rho$ the density, $w$ the fault thickness, and $C$ the heat capacity that we assume is $1 \mathrm{~J} / \mathrm{g}^{\circ} \mathrm{C}$ [Andersen and Austrheim, 2006; Nielsen et al., 2010]. Note that in equations (3a) and (3b) only the fracture energy $G$ is used to estimate the temperature rise (frictional heat is calculated by assuming $E_{H}=0$ ). Of course, if melting occurs, the latent heat of fusion needs to be included and may suppress additional temperature rise as the melt layer forms.

[14] Figure 4 shows predicted temperature rise $(\Delta T)$ for various slipping zone thicknesses. Field observations show a wide range of fault vein thicknesses, with most in the 0.1 $\mathrm{cm}$ to $2-3 \mathrm{~cm}$ range in subcontinental environments (deep continental crust) [Obata and Karato, 1995; Ueda et al., 2008] as well as subduction zones [Andersen and Austrheim, 2006; Andersen et al., 2008]. Given the low thermal diffusivity of rocks $\left(\sim 1.5 \mathrm{~mm}^{2} / \mathrm{s}\right)$, thicknesses are not expected to be much larger for second-long rupture durations observed here. A temperature of $1400-1800^{\circ} \mathrm{C}$ is required to melt peridotite and gabbroic rocks [Nielsen et al., 2010; Del Gaudio et al., 2009], thus depending on the temperature of the slab a $\Delta T$ of between $600-1000^{\circ} \mathrm{C}$ is needed for melting to occur. Our data (see Figure 4) suggests that for a $1 \mathrm{~cm}$ thick layer, frictional melting may occur for $0.4 \mathrm{~m}$ of slip, corresponding to $M_{w}$ 4.7. If the layer thickness were $3 \mathrm{~cm}$, a slip of $0.75 \mathrm{~m}$ would be required, corresponding to $M_{w}$ 5.0. Although these large temperature rises point to a shear runaway mechanism, we note that fluids and dehydration may still play an important role because the onset of viscous creep should occur in 


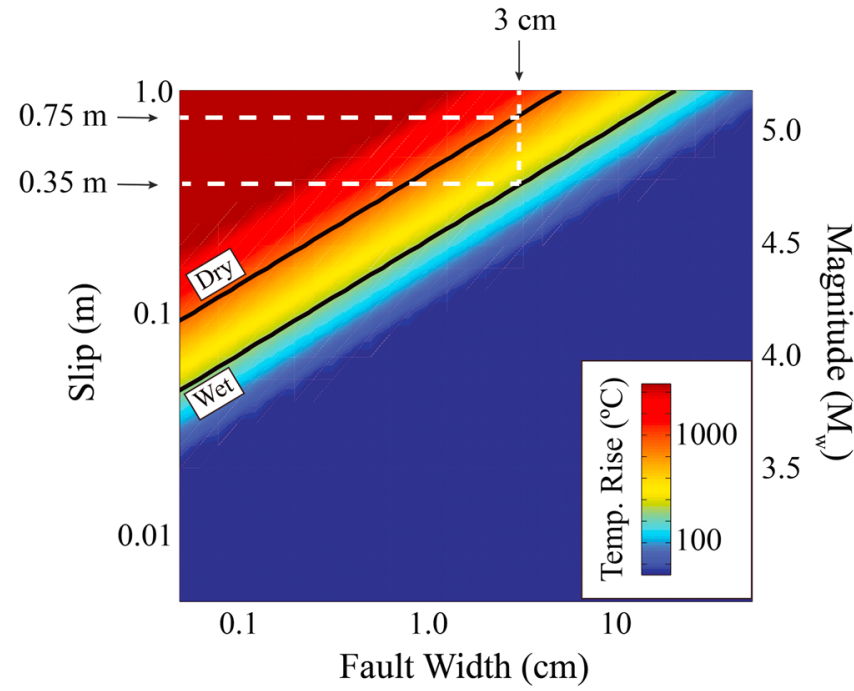

Figure 4. Temperature rise due to fracture energy as a function of slip and width of fault. Inferred temperature rise for intermediate-depth earthquakes in this study assuming only fracture energy $G$ is converted to heat. Estimates represent a lower bound because it is assumed that the frictional energy $E_{H}$ is zero. The thickness of the layer $w$ where temperature rises may be between 0.1 and $10 \mathrm{~cm}$ based on field observations [John et al., 2009]. Thick black lines show the expected temperature of fusion for dry peridotite and $\mathrm{H}_{2} \mathrm{O}$-bearing peridotite [Nielsen et al., 2010; Till et al., 2012] assuming host rock temperature of $600^{\circ} \mathrm{C}$. Based on our results, for a $3 \mathrm{~cm}$ thick layer, frictional melting may readily occur for $M 5+$ earthquakes with slips of $75 \mathrm{~cm}$ and $35 \mathrm{~cm}$ for dry and wet peridotite, respectively.

preexisting fine-grained shear zones [Keleman and Hirth, 2007], and fine-grained products can result from dehydration reactions [Jung et al., 2009; Chernak and Hirth, 2011]. Moreover, in the presence of fluids, melting temperatures are reduced. Melting could begin at $800-1000^{\circ} \mathrm{C}$ for an $\mathrm{H}_{2} \mathrm{O}$-saturated peridotite [Till et al., 2012], requiring $\Delta T$ of only $200-400^{\circ} \mathrm{C}$ for production of melt, corresponding to $M_{w}>4.3$ (see Figure 4).

\section{Discussion}

[15] The scaling of stress drop and apparent stress as a function of magnitude is higher than what is generally observed in shallow earthquakes [Baltay et al., 2010] or reported for deep earthquakes [Frohlich, 2006]. Bandwidth limitations or inappropriate attenuation corrections may artificially manifest as size dependence [Ide and Beroza, 2001], and upon careful scrutiny some shallow earthquake populations that appear to show strong scaling [Mori et al., 2003; Takahashi et al., 2005] may not be robust. We have carefully scrutinized the observed scaling we find for BN earthquakes. The Green's function method used here includes the frequency-dependent attenuation corrections empirically, yet scaling is still observed for BN earthquakes $M_{w}>4.0$, where bandwidth limitations are not an issue. Additionally, the $\mathrm{BN}$ hosts a number of repeating earthquakes with very similar spectral shapes and corner frequencies but significantly different seismic moments.

[16] There are good reasons to believe that our temperature rise estimates may be lower bounds. First, in equation (3) we neglect frictional energy $\left(E_{H}\right)$. That is, only fracture energy is used to estimate the temperature rise. Second, in the relation between the corner frequency and the source dimension and stress drop we assume a rupture velocity of $0.9 \beta$. Given the small radiation efficiency, actual rupture velocities could be lower. For a crack model, the rupture velocity $V_{R}$ should follow $\eta_{R}=\left(V_{\mathrm{R}} / \beta\right)$ [Kanamori et al., 1998], which in our case would be as low as $V_{R}=0.2 \beta$. If we assume rupture velocities are half as large, for example $0.45 \beta$, our estimated stress drops would be 8 times as high and temperature rise would be at least 10 times higher than depicted in. In the supporting information we show $\Delta T$ estimates under different assumptions of rupture velocity and fault shape and average frictional stress (Figure 4).

[17] For typical shear zone widths $(1-3 \mathrm{~cm})$ assumed here, temperatures could rise by more than $600^{\circ} \mathrm{C}$ for moderatesized earthquakes. Previous studies [Andersen et al., 2008] suggest that high stress drops (100-750 MPa) are required for these mechanisms to operate. Our stress drop estimates are on the lower end of that range; however, as noted above, our estimates are likely to be lower bounds. Note also that field-based stress drop estimates represent a point on a fault (area $\sim \mathrm{m}^{2}$ ) while our stress drop are averaged over the entire fault (area $\sim \mathrm{km}^{2}$ ). Our estimates of fracture energy for earthquakes $M_{w}>4.0$ are in the $1-100 \mathrm{MJ} / \mathrm{m}^{2}$ range, similar to fracture energies $\left(10-30 \mathrm{MJ} / \mathrm{m}^{2}\right)$ observed for frictional melting of peridotite in laboratory experiments [Di Toro et al., 2011]. Most of this energy is thought to be converted to heat based on theoretical and field investigations [Ma et al., 2006; Cocco and Tinti, 2008]. Because earthquakes occur at higher normal stresses, the extrapolation from laboratory experiments to the real Earth will likely lower these fracture energy estimates [Di Toro et al., 2011].

[18] Our results support the thermal runaway mechanism for intermediate-depth earthquake rupture. A distinct mechanism from that for shallow earthquakes may help explain other distinct characteristics of intermediate-depth seismicity. Although thermal runaway may operate once slip has initiated, there is still the question of how slip initiates. Our results reveal the weakening process in an integrated way as it manifests in macroscopically observable quantities. These quantities may fail to capture important aspects of the failure process [e.g., Abercrombie and Rice, 2005]. Moreover, laboratory studies have suggested a complex evolution of the dynamic shear strength [Hirose and Shimamoto, 2005; Brown and Fialko, 2012] with two phases of weakening separated by strengthening before melting. The resolution of the seismic observations presented here prevents us from constraining such details both temporarily and spatially but represents the first steps to a better understanding of the mechanisms involved in intermediate-depth earthquakes.

[19] Acknowledgments. The authors would like to thank Cliff Frohlich and an anonymous reviewer for their constructive comments. This work was supported by NSF grant EAR-1045684. The RSNC data were prepared and distributed by the CGS Working Group. The CGS Working group consists of Patricia Pedraza, Jose Faustino Blanco, and Esteban Poveda. G.P. would like to thank Fabio Ferri and Felipe Peña for their helpful discussions.

[20] The Editor thanks Cliff Frohlich and an anonymous reviewer for their assistance in evaluating this paper.

\section{References}

Abercrombie, R. E., and J. R. Rice (2005), Can observations of earthquake scaling constrain slip weakening?, Geophys. J. Int., 162, 406-424. 
Allmann, B. P., and P. M. Shearer (2009), Global variations of stress drop for moderate to large earthquakes, J. Geophys. Res., 114, B01310, doi:10.1029/ 2008JB005821.

Andersen, T. B., and H. Austrheim (2006), Fossil earthquakes recorded by pseudotachylytes in mantle peridotite from the Alpine subduction complex of Corsica, Earth Planet. Sci. Lett., 242, 58-72, doi:10.1016/j. eps1.2005.11.058.

Andersen, T. B., K. Mair, H. Austrheim, Y. Y. Podladchikov, and J. C. Vrijmoed (2008), Stress release in exhumed intermediate-deep earthquakes determined from ultramafic pseudotachylyte, Geology, 36, 995-998.

Baltay, A., G. Prieto, and G. C. Beroza (2010), Radiated seismic energy from coda measurements and no scaling in apparent stress with seismic moment J. Geophys. Res., 115, B08314, doi:10.1029/2009JB006736.

Beeler, N. M., T.-F. Wong, and S. H. Hickman (2003), On the expected relationships among apparent stress, static stress drop, effective shear fracture energy and efficiency, Bull. Seismol. Soc. Am., 93(3), 1381-1389.

Bouchon, M., and P. Ihmle (1999), Stress drop and frictional heating during the 1994 deep Bolivia earthquake, Geophys. Res. Lett., 26(23), 3521-3524.

Braeck, S., and Y. Y. Podladchikov (2007), Spontaneous thermal runaway as an ultimate failure mechanism of materials, Phys. Rev. Lett., 98, 095504, doi:10.1103/PhysRevLett.98.095504.

Brown, K., and Y. Fialko (2012), "Melt welt" mechanism of extreme weakening of gabbro at seismic slip rates, Nature, 488, 638-641.

Brune, J. N. (1970), Tectonic stress and seismic shear waves from earthquakes, J. Geophys. Res., 75, 4997-5009.

Cardwell, R. K., D. S. Chinn, G. F. Moore, and D. L. Turcotte (1978) Frictional heating on a fault zone with finite thickness, Geophys. J. R. Astron. Soc., 52, 525-530.

Chernak, L. J., and G. Hirth (2011), Syndeformational antigorite dehydration produces stable fault slip, Geology, 39, 847-850, doi:10.1130/G31919.1.

Cocco, M., and E. Tinti (2008), Scale dependence in the dynamics of earthquake propagation: Evidence from seismological and geological observations, Earth Planet. Sci. Lett., 273, 123-131.

Del Gaudio, P., G. Di Toro, R. Han, T. Hirose, S. Nielsen, T. Shimamoto, and A. Cavallo (2009), Frictional melting of peridotite and seismic slip, J. Geophys. Res., 114, B06306, doi:10.1029/2008JB005990.

Di Toro, G., T. Hirose, S. Nielsen, G. Pennacchioni, and T. Shimamoto (2006), Natural and experimental evidence of melt lubrication of faults during earthquakes, Science, 311, 647-649.

Di Toro, G., R. Han, T. Hirose, N. De Paola, S. Nielsen, K. Mizoguchi, F. Ferri, M. Cocco, and T. Shimamoto (2011), Fault lubrication during earthquakes, Nature, 471, 494-498.

Frohlich, C. (2006), Deep Earthquakes, Cambridge Univ. Press, Cambridge.

Frohlich, C., and Y. Nakamura (2009), The physical mechanisms of deep moonquakes and intermediate-depth earthquakes: How similar and how different?, Phys. Earth Planet. Inter., 173, 365-374.

Green, H. W., and H. Houston (1995), The mechanics of deep earthquakes, Annu. Rev. Earth Planet. Sci., 23, 169-213.

Gusev, A., M. Radulian, M. Rizescu, and G. F. Panza (2002), Source scaling of intermediate-depth Vrancea earthquakes, Geophys. J. Int., 151, 879-889.

Hacker, B. R., S. M. Peacock, G. A. Abers, and S. D. Holloway (2003), Subduction factory 2. Are intermediate-depth earthquakes in subducting slabs linked to metamorphic dehydration reactions?, J. Geophys. Res., 108(B1, 2030), doi:10.1029/2001JB001129.
Hirose, T., and T. Shimamoto (2005), Growth of molten zone as a mechanism of slip weakening of simulated faults in gabbro during frictional melting, J. Geophys. Res., 110, B05202, doi:10.1029/2004JB003207.

Houston, H. (2007), Deep earthquakes, in Treatise on Geophysics, Vol. 4: Deep Earthquakes, vol. 11, edited by G. Schubert, pp. 321-350, Elsevier, Amsterdam, The Netherlands.

Ide, S., and G. C. Beroza (2001), Does apparent stress vary with earthquake size?, Geophys. Res. Lett., 28, 3349-3352.

John, T., S. Medvedev, L. H. Rupke, T. B. Andersen, Y. Y. Podladchikov, and H. Austrheim (2009), Generation of intermediate-depth earthquakes by self localizing thermal runaway, Nat. Geosci., 2, 137-140, doi:10.1038/NGEO419.

Jung, H., H. W. Green II, and L. F. Dobrzhinetskaya (2004), Intermediatedepth earthquake faulting by dehydration embrittlement with negative volume change, Nature, 428, 545-549, doi:10.1038/nature02412.

Jung, H., Y. Fei, P. Silver, and H. W. Green (2009), Frictional sliding in serpentine at very high pressure, Earth Planet. Sci. Lett., 277, 273-279, doi:10.1016/j.eps1.2008.10.019.

Kanamori, H., D. L. Anderson, and T. H. Heaton (1998), Frictional melting during the rupture of the 1994 Bolivian earthquake, Science, 279, 839-842.

Keleman, P. B., and G. Hirth (2007), A periodic shear-heating mechanism for intermediate-depth earthquakes in the mantle, Nature, 446, 787-790.

Kikuchi, M., and M. Ishida (1993), Source retrieval for deep local earthquakes with broadband records, Bull. Seismol. Soc. Am., 83, 1855-1870.

Ma, K. F., et al. (2006), Slip zone and energetics of a large earthquake from the Taiwan Chelungpu-fault Drilling Project (TCDP), Nature, 444, 473-476.

Mori, J., R. E. Abercrombie, and H. Kanamori (2003), Stress drops and radiated energies of aftershocks of the 1994 Northridge, California, earthquake, J. Geophys. Res., 108(B11, 2545), doi:10.1029/200JB000474.

Nielsen, S., P. Mosca, G. Giberti, G. Di Toro, T. Hirose, and T. Shimamoto (2010), On the transient behavior of frictional melt during seismic slip, J. Geophys. Res., 115, B10301, doi:10.1029/2009JB007020.

Obata, M., and S. Karato (1995), Ultramafic pseudotachylite from the Balmuccia peridotite, Ivrea Verbano Zone, northern Italy, Tectonophysics, 242, 313-328, doi:10.1016/0040-1951(94)00228-2.

Oth, A., S. Parolai, D. Bindi, and F. Wenzel (2009), Source spectra and site response from $\mathrm{S}$ waves of intermediate-depth Vrancea, Romania, earthquakes, Bull. Seismol. Soc. Am., 99(1), 235-254.

Prieto, G. A., P. M. Shearer, F. L. Vernon, and D. Kilb (2004), Earthquake source scaling and self-similarity estimation from stacking $\mathrm{P}$ and $\mathrm{S}$ spectra, J. Geophys. Res., 109, B08310, doi:10.1029/2004JB003084.

Prieto, G. A., G. C. Beroza, S. A. Barrett, G. A. López, and M. Florez (2012) Earthquake nests as natural laboratories for the study of intermediate-depth earthquake mechanics, Tectonophysics, 570-571, 42-56, doi:10.1016/j. tecto.2012.07.019.

Radulian, M., and M. Popa (1996), Scaling of the source parameters for the Vrancea intermediate depth earthquakes, Tectonophysics, 261, 67-81.

Takahashi, T., H. Sato, M. Ohtake, and K. Obara (2005), Scale dependence of apparent stress for earthquakes along the subducting Pacific Plate in northeastern Honshu, Japan, Bull. Seismol. Soc. Am., 95(4), 1334-1345.

Till, C. B., T. L. Gove, and A. C. Withers (2012), The beginnings of hydrous mantle wedge melting, Contrib. Mineral. Petrol., 163, 669-688.

Ueda, T., M. Obata, G. Di Toro, K. Kanagawa, and K. Ozawa (2008), Mantle earthquakes frozen in mylonitized ultramafic pseudotachylytes of spinellherzolite facies, Geology, 36(8), 607-610, doi:10.1130/G24739A.1. 